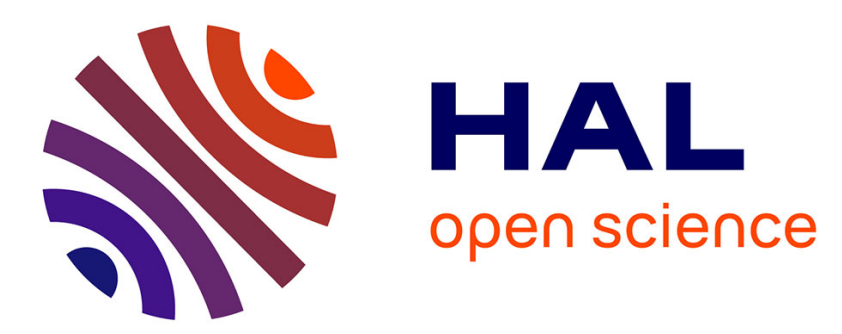

\title{
Reactions of Nitrogen and Oxygen Surface Groups in Nanoporous Carbons under Inert and Reducing Atmospheres
}

B. Xiao, Jean-Paul Boudou, Mark Thomas

\section{- To cite this version:}

B. Xiao, Jean-Paul Boudou, Mark Thomas. Reactions of Nitrogen and Oxygen Surface Groups in Nanoporous Carbons under Inert and Reducing Atmospheres. Langmuir, 2005, 21, pp.3400-3409. 10.1021/la0472495 . bioemco-00156846

\section{HAL Id: bioemco-00156846 https://hal-bioemco.ccsd.cnrs.fr/bioemco-00156846}

Submitted on 22 Jun 2007

HAL is a multi-disciplinary open access archive for the deposit and dissemination of scientific research documents, whether they are published or not. The documents may come from teaching and research institutions in France or abroad, or from public or private research centers.
L'archive ouverte pluridisciplinaire HAL, est destinée au dépôt et à la diffusion de documents scientifiques de niveau recherche, publiés ou non, émanant des établissements d'enseignement et de recherche français ou étrangers, des laboratoires publics ou privés. 


\title{
Reactions of Nitrogen and Oxygen Surface Groups in Nanoporous Carbons under Inert and Reducing Atmospheres
}

\author{
B. Xiao, J. P. Boudou, and K. M. Thomas* \\ Northern Carbon Research Laboratories, School of Natural Sciences, Bedson Building, \\ University of Newcastle upon Tyne, Newcastle upon Tyne, NE1 7RU United Kingdom, and \\ University Pierre et Marie Curie, CNRS 4, Place Jussieu, 75252 Paris Cedex 05, France
}

\begin{abstract}
The reactions of surface functional groups have an important role in controlling conversion of char nitrogen to NOx during coal combustion. This study involved an investigation of the thermal stability and reactions of nitrogen surface functional groups in nanoporous carbons. Four suites of carbons, which were used as models for coal chars, were prepared with a wide range of nitrogen and oxygen contents and types of functional groups. The porous structures of the carbons were characterized by gas adsorption methods while chemical analysis, X-ray photoelectron spectroscopy, and X-ray near edge structure spectroscopy were used to characterize the surface functional groups. Temperature programmed desorption and temperature programmed reduction methods were used to study the reactivity of the surface functional groups during heat treatment under inert and reducing conditions. Heat treatment studies show that the order of stability of the functional groups is quaternary nitrogen > pyridinic > pyrrolic > pyridine $N$-oxide. Pyridine $N$-oxide surface groups desorb $\mathrm{NO}$ and form $\mathrm{N}_{2}$ via surface reactions at low temperature. Pyrrolic and pyridinic functional groups decompose and react with surface species to give $\mathrm{NH}_{3}, \mathrm{HCN}$, and $\mathrm{N}_{2}$ as desorption products, but most pyrrolic groups are preferentially converted to pyridinic and quaternary nitrogen. The main desorption product is $\mathrm{N}_{2}$. Approximately 15-40 wt \% of the original nitrogen was retained in the carbons mainly as quaternary nitrogen after heat treatment to $1673 \mathrm{~K}$. The results are discussed in terms of decomposition ranges for surface functional groups and reaction mechanisms of surface species.
\end{abstract}

\section{Introduction}

The environmental impact of coal combustion for power generation is a major concern. ${ }^{1}$ Technologies have been developed to make coal combustion more environmentally acceptable, including improvements in combustion efficiencies, flue gas desulfurization, and the development of combustion technologies for minimizing NOx emissions. In the case of the latter, this often involves the use of lower combustion temperatures to reduce emissions due to the Zeldovich mechanism and devolatilization of the coal in a low oxygen concentration environment. This leads to problems with carbon burn-out leading to lower efficiency, and nitrogen bound in the carbon char structure after devolatilization becomes the major source ofNOx.1,2

Nitrogen is present in the organic structure of coal, in the form of pyridinic, pyrrolic, and quaternary functionalities,,$^{3-9}$ and a large amount is retained in the char after the devolatilization process. The forms of nitrogen in coal chars ${ }^{10,11}$ and chars derived from nitrogen-containing pure

* To whom all correspondence should be addressed. E-mail: mark.thomas@ncl.ac.uk.

(1) Molina, A.; Eddings, E. G.; Pershing, D. W.; Sarofim, A. F. Prog. Energy Combust. Sci. 2000, 26, 507.

(2) Harding, A. W.; Brown, S. D.; Thomas, K. M. Combust. Flame 1996, 107 (4), 336

(3) Thomas, K. M. Fuel 1997, 76, 457.

(4) Boudou, J. P.; Mariotti, A.; Oudin, J. L. Fuel 1984, 63, 1508.

(5) Burchill, P.; Welch, L. S. Fuel 1989, 68, 100.

(6) Mullins, O. C.; Mitra-Kirtley, S.; van Elp, J.; Cramer, S. P. Appl. Spectrosc. 1993, 47, 1268.

(7) Wallace, S.; Bartle, K. D.; Perry, D. L. Fuel 1989, 68, 1450.

(8) Kelly, M. D.; Buckley, A. N.; Nelson, P. F. Proceedings of the International Conference on Coal Science, University ofNewcastle-UponTyne, UK, Sept 16-20, 1991; Butterworth-Heinemann: Oxford, 1991; p 356 .

(9) Wojtowicz, M. A.; Pels, J. R.; Moulijn, J. A. Fuel 1994, 73, 1416. organic compounds and polymers ${ }^{12-14}$ have been studied by X-ray photoelectron spectroscopy (XPS) and X-ray absorption near edge structure (XANES) spectroscopy $\mathbf{y}_{14,15}$ and are pyridinic, pyrrolic, pyridone, pyridine $N$-oxide, amine, and quaternary nitrogen.12-14

NOx release during coal combustion is related to the following mechanisms: (i) evolution of nitrogen content and functionality during pyrolysis and combustion, (ii) release of char nitrogen species to the gas phase and its further oxidation, and (iii) rate of NO reaction with the char. $^{1} \mathrm{NO}$ is the primary product of char nitrogen combustion. The other nitrogen products of carbon char combustion, $\mathrm{N}_{2}$ and $\mathrm{N}_{2} \mathrm{O}$, are thought to the result from either secondary homogeneous or heterogeneous surface reactions. Nitrogen functionalities may react or decompose during pyrolysis and there is evidence for the formation ofpyridone and pyridine $N$-oxide functional groups during combustion and gasification. ${ }^{14,16}$ All these factors influence the relative rates of various reactions and, therefore, product distributions and are critical in determining the conversion of char nitrogen to NO. ${ }_{1,2}$

(11) Gong, B.; Buckley, A. N.; Lamb, R. N.; Nelson, P. F. Surf. Interface Anal. 1999, 28 (1), 126.

(12) Kelemen, S. R.; Gorbaty, M. L.; Kwiatek, P. J.; Fletcher, T. H.; Watt, M.; Solum, M. S.; Pugmire, R. J. Energy Fuels 1998, 12 (1), 159.

(13) Pels, J. R.; Kapteijn, F.; Moulijn, J. A.; Zhu, Q.; Thomas, K. M. Carbon 1995, 33, 1641.

(14) Stanczyk, K.; Dziembaj, R.; Piwowarska, Z.; Witkowski, S. Carbon 1995, 33, 1383.

(15) Zhu, Q.; Money, S. L.; Russell, A. E.; Thomas, K. M. Langmuir 1997, $13,2149$.

(16) Jones, J. M.; Zhu, Q.; Thomas, K. M. Carbon 1999, 37, 1123.

(17) Kapteijn, F.; Moulijn, J. A.; Matzner, S.; Boehm, H.-P. Carbon 1999,37 (7), 1143 . 
The release of char nitrogen during combustion involves reactions on the surface and in the pores of the carbon, and nitrogen is retained in the char.,317 The NO-carbon reaction is important, ${ }^{18-26}$ and oxygen enhances the NOcarbon reaction while decreasing the nitrous oxide carbon reaction. This is thought to be related to the different modes of adsorption of $\mathrm{NO}$ and $\mathrm{N}_{2} \mathrm{O} .{ }^{18} \mathrm{~N}_{2}$ is the major product of the carbon-NO reaction, and the mechanism of this reaction has been studied in some detail. Interestingly, NO has been shown to form cyano functionalities on carbon surfaces which can form HCN during combustion ${ }_{26}$ Small amounts of reactive intermediate species, $\mathrm{HCN}$ and $\mathrm{C}_{2} \mathrm{~N}_{2}$, indicative of surface reactions, were evolved during temperature programmed combustion. ${ }_{27}$ The complexity of the process has led to applications of $a b$ initio molecular orbital calculations and density functional theory to understand the surface chemistry of desorption of surface species and reactions of nitrogen oxides in the presence of surface oxygen species on the surface of carbon, to understand the reduction of NO during char combustion ${ }^{28-34}$ Density functional theory has been used to study the reaction of $\mathrm{NO}$ with charbound nitrogen and the role of preadsorbed oxygen. ${ }^{17}$ The calculations indicate that the presence of adsorbed oxygen on the carbon basal plane containing nitrogen enhances the reduction of $\mathrm{NO}$ to $\mathrm{N}_{2}$.

In this study, the thermal evolution and reactions of nitrogen surface species under inert and reducing conditions and desorption ofnitrogen species were investigated in four suites of carbons. These carbons were used as models for coal chars to avoid possible catalytic effects due to the presence of inorganic materials. Inert and hydrogen-rich conditions are relevant to the char devolatilization stage. Reactions of nitrogen, oxygen, and hydrogen surface groups were investigated using temperature programmed desorption (TPD) and temperature programmed reduction (TPR). The results are discussed in relation to surface groups identified by XANES and XPS to gain an improved insight into the role of specific functional groups in surface reactions involved in the release of nitrogen-containing species during char pyrolysis, gasification, and combustion.

(17) Ashman P. J·Haynes, B. S ; Buckiey, A N · Nelson, P. F Symp.

(Int.) Combust., [Proc.], 27th 1998, 2, 3069

(18) Yamashita, H.; Tomita, A.; Yamada, H.; Kyotani, T.; Radovic L. R. Energy Fuels 1993, 7, 85.

(19) Aarna, I.; Suuberg, E. M. Symp. (Int.) Combust., [Proc.], 27th

1998, 2,3061

(20) Aarna, I.; Suuberg, E. M. Fuel 1997, 76, 475.

(21) Chan, L. K.; Sarofim, A. F.; Beer, J. M. Combust. Flame 1983, 52 (1), 37

(22) Chambrion, P.; Orikasa, H.; Suzuki, T.; Kyotani, T.; Tomita, A. Fuel 1997, 76, 493

(23) Furusawa, T.; Tsunada, M.; Tsujimura, M.; Adschiri, T. Fuel 1985, 64, 1306

(24) Yang, J.; Mestl, G.; Herein, D.; Schlogl, R.; Find, J. Carbon 2000, 38, 715; Carbon 2000, 38, 729 .

(25) Aarna, I.; Suuberg, E. M. Energy Fuels 1999, 13, 1145.

(26) Chambrion, P.; Kyotani, T.; Tomita, A. Symp. (Int.) Combust., [Proc.] 27th 1998, 2, 3053.

(27) Jones, J. M.; Harding, A. W.; Brown, S. D.; Thomas, K. M. Carbon 1995, 33,833 .

(28) Kyotani, T.; Tomita, A. J. Phys. Chem. B 1999, 103, 3434.

(29) Montoya, A.; Truong, T. N.; Sarofim, A. F. J.Phys. Chem. A $\mathbf{2 0 0 0 , 1 0 4 , 8 4 0 9}$

(30) Zhu, Z. H.; Finnerty, J.; Lu, G. Q.; Yang, R. T. J. Phys. Chem. B 2001, 105, 821

(31) Montoya, A.; Truong, T. T.; Mondragon, F.; Truong, T. N. J. Phys. Chem. A 2001, 105, 6757.

(32) Wongtanakitcharoen, S.; Tatiyakiatisakun, T.; Rirksomboon, T.; Long, R. Q.; Osuwan, S.; Malakul, P.; Yang, R. T. Energy Fuels 2001, 15,1341 .

(33) Byrne, C. P.; Yang, R. T.; Zhu, Z. H.; Lu, G. Q. J. Phys. Chem. B 2002, 106, 2592

(34) Zhu, Z. H.; Lu, G. Q. Energy Fuels 2003, 17, 1057.

\section{Experimental Section}

2.1. Precursor Materials Used. Carbon Material Used. Commercially available coconut shell derived carbon $\mathrm{G}$ prepared by physical activation using steam at $1173 \mathrm{~K}$ was used in this study. This carbon was supplied by Pica, Vierzon, France.

Polyacrylonitrile (PAN) Derived Carbon. PAN powder supplied by Aldrich Chemical Co. was pretreated in air at $473 \mathrm{~K}$ for $1 \mathrm{~h}$. The pretreated PAN was heated at a rate of $3 \mathrm{~K} \mathrm{~min}^{-1}$ to 1173 $\mathrm{K}$ in argon. The argon flow was then changed to $\mathrm{CO}_{2}$, and the char was gasified at $1173 \mathrm{~K}$ for $4 \mathrm{~h}$. This gave a carbon, designated code PANC, which had a burnoff -60 wt $\%$.

Acridine Carbon. Acridine (99\% pure) was obtained from Aldrich Chemical Co. Acridine was carbonized under argon at a pressure of $4.1 \mathrm{MPa}$ with a heating rate of $1 \mathrm{~K} \mathrm{~min}^{-1}$ to a final temperature of $873 \mathrm{~K}$ and held at the heat treatment temperature (HTT) for $1 \mathrm{~h}$ to give carbon AD873. The sample produced by high-pressure carbonization was then heat treated at atmospheric pressure to $1073 \mathrm{~K}$ at a heating rate of $4 \mathrm{~K} \mathrm{~min}^{-1}$ under argon and held at the HTT for $1 \mathrm{~h}$ to give carbon AD1073.

2.2. Treatment Procedures. PANC and G were subjected to low temperature chemical oxidation followed by heat treatment to systematically vary the type and concentration of oxygen functional groups. This gave two series of carbons with (a) low nitrogen contents $(\wedge-1$ wt \%) derived from $\mathrm{G}$ and (b) a high nitrogen content $(\wedge 8 \mathrm{wt} \%)$ series derived from PANC. Carbons $\mathrm{G}$ and chemically oxidized G (GN) were treated with ammonia. It was envisaged that different types of functional groups might be incorporated by high-temperature gasification compared with nitrogen incorporation during the carbonization procedure. This gave a third series of carbons with a range nitrogen contents. A fourth series of carbons was prepared by carbonization of a starting material with well-defined pyridinic nitrogen functionality (acridine). Both the ammonia treated and acridine carbon samples were partially combusted at $1073 \mathrm{~K}$ to incorporate carbonyl groups for comparison with the low-temperature chemical oxidation method. ${ }^{35}$ The four series of carbons (see Table 1) had a wide range of nitrogen and oxygen contents and, also, very low ash contents (see Table 2).

Chemical Oxidation Treatment. G and PANC were refluxed in a $7.5 \mathrm{M} \mathrm{HNO}_{3}$ solution for $48 \mathrm{~h}$. The oxidized carbons were Soxhlet extracted with water, to remove residual $\mathrm{HNO}_{3}$ and any soluble materials, until the $\mathrm{pH}$ of the aqueous extract was constant, and vacuum-dried at $348 \mathrm{~K}$. The carbons derived from PANC and G were designated sample codes PANCN and GN, respectively.

Ammonia Treatment. G and GN were heated to $1073 \mathrm{~K}$ at a heating rate of $3 \mathrm{~K} \mathrm{min-1}$ in ammonia (flow rate $\wedge-200 \mathrm{~cm}^{3} \mathrm{~min}-1$ ) and held at the maximum temperature for $3 \mathrm{~h}$. The treated carbon was cooled in ammonia to room temperature. The carbon was then Soxhlet extracted with water to remove residual ammonia and any soluble material. The sample was vacuum-dried at 348 $\mathrm{K}$. The carbons derived from $\mathrm{G}$ and $\mathrm{GN}$ were designated sample codes GA and GNA, respectively.

Heat TreatmentProcedures. PANCN and GN were heat treated to provide a suite of carbons where the oxygen functional groups of various thermal stabilities were varied progressively. The carbon samples were heat treated to the HTT at $3 \mathrm{~K} \mathrm{~min}^{-1}$ and held at the HTT for $1 \mathrm{~h}$. The resultant carbons were designated using the code of original carbon and the HTT in kelvin; for example, GN573 represents GN heat treated to $573 \mathrm{~K}$ and held at the HTT for $1 \mathrm{~h}$.

Partial Combustion Treatment. GNA, GA, and AD1073 were partially gasified in $20 \%$ oxygen/argon until the specified extent of burnoff. The samples were then cooled in argon to room temperature. The carbons were given sample codes designated by the extent of burnoff; for example, AD1073 with a burnoff of $56 \%$ was given the code AD1073-B56.

2.3. Chemical Analyses. Proximate analyses were performed by the method described previously. ${ }^{36}$ Elemental analyses were determined by Microanalytical Services, Oakhampton, U.K.

(36) Figueiredo, J. L.; Pereira, M. F. R.; Freitas, M. M. A.; Orfao, J. J. M. Carbon 1999, 37, 1379 ,

(37) Grant, K. A.; Zhu, Q.; Thomas, K. M. Carbon 1994, 32, 883. 
Table 1. Methods of Preparation of the Carbon Samples

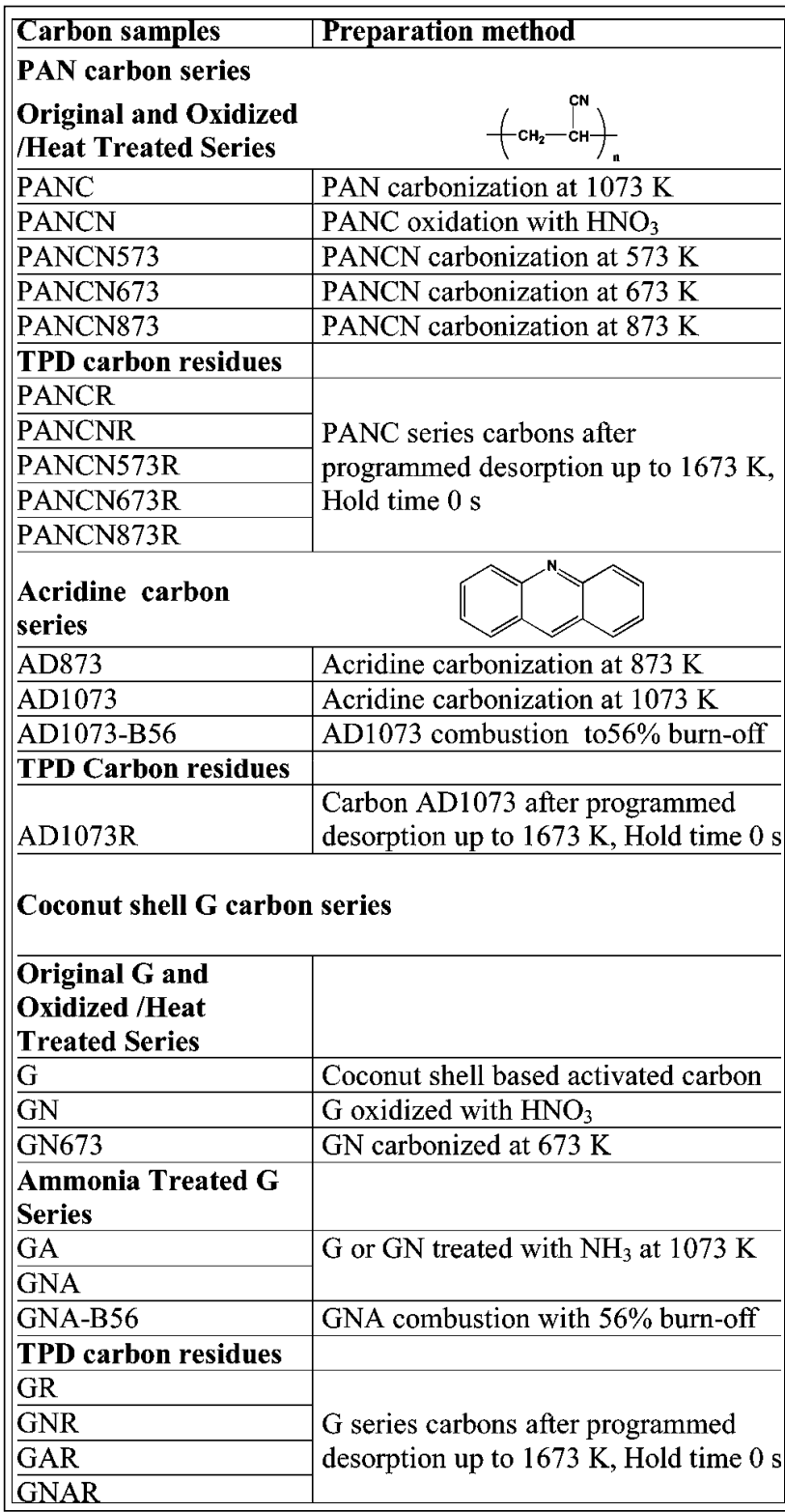

2.4. Porous Structure Characterization. The micropore and total pore volumes of active carbons used were evaluated by the adsorption of $\mathrm{CO}_{2}$ at $273 \mathrm{~K}$ and $\mathrm{N}_{2}$ at $77 \mathrm{~K}$, respectively. The measurements were carried out using a Hiden Analytical, Ltd., intelligent gravimetric analyzer. The micropore volume was obtained from the $\mathrm{CO}_{2}$ adsorption data $\left(p / p^{0}, 0-0.03\right)$ by extrapolation of the Dubinin-Radushkevich equation ${ }^{37}$ to $\left.p / p^{0}\right) 1$. An adsorbed phase density ${ }_{(\mathrm{PCO})}$ of $1.023 \mathrm{~cm}_{3 \mathrm{~g}^{-1}} \mathrm{w}$ as used in the calculation. The total pore volume was obtained from the uptake of $\mathrm{N}_{2}$ at $\left.p / p^{0}\right) 1\left(\mathrm{~F}_{\left.\mathrm{N}_{2}\right)} 0.8081 \mathrm{~cm}^{3} \mathrm{~g}-1\right)$.

2.5. Functional Group Characterization. XANES. Nitrogen K-edge measurements were performed at the Laboratoire pour l'Utilisation du Rayonnement Electromagne'tique (LURE, Orsay, France) on the VUV Super-Aco storage ring. They were carried out at room temperature and 10-10 Torr on the Sacemor experiment connected to the SA72 beam line, equipped with a high-energy TGM monochromator (resolution of ${ }^{\wedge}-0.2 \mathrm{eV}$ at the nitrogen $\mathrm{K}$ edge). The spectra were recorded with total-electronyield detection, normalized from the fluctuations in the X-ray intensity by dividing the signal by that of a copper grid freshly

(37) Dubinin, M. M. In Characterization of Porous Solids; Sing, K. S. W., Ed.; Society of Chemical Industries: London, 1979; Vol. 1, pp $1-11$.
Table 2. Proximate and Elemental Analyses for the Carbons Used in This Study $a$

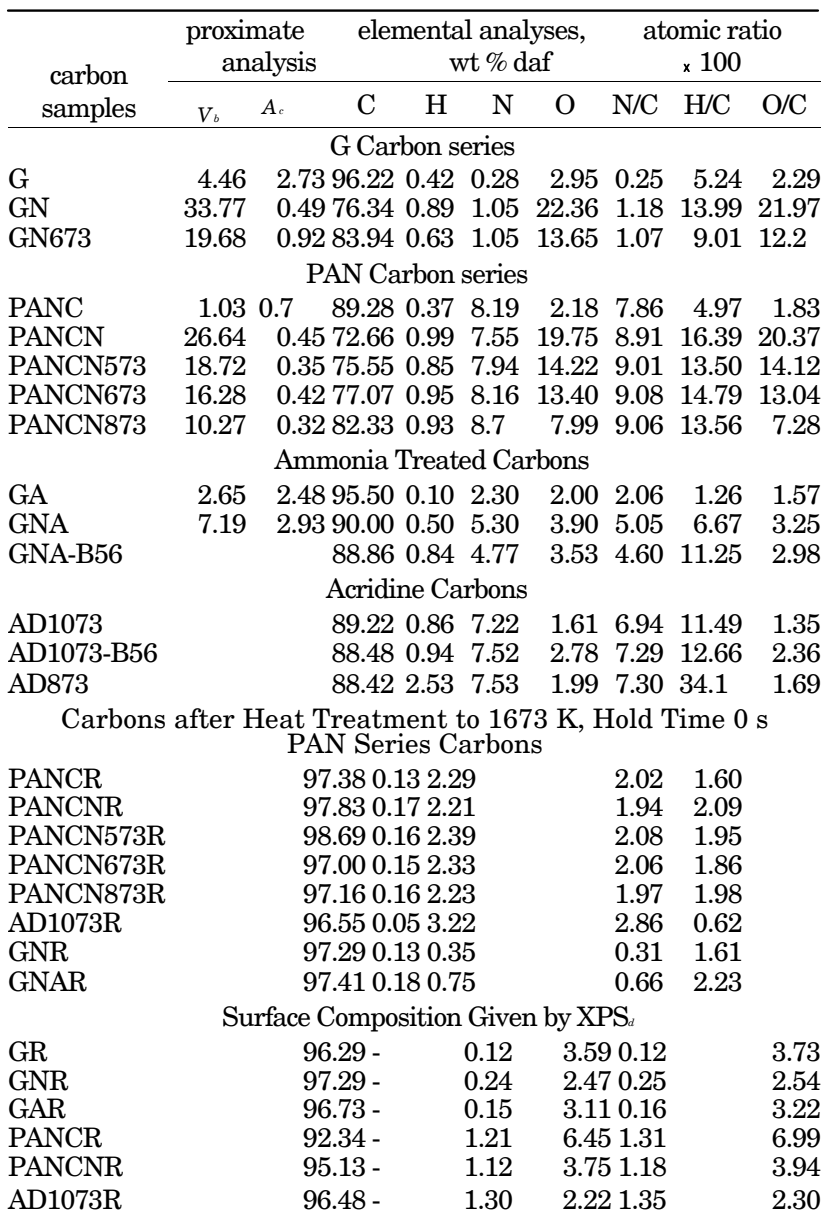

${ }_{a}$ Carbons GA, GNA, and AD were all treated to $1073 \mathrm{~K}$, and, therefore, the volatile matter contents were negligible and were not determined. ${ }^{b}$ Volatile content, wt $\%$ daf. ${ }^{c}$ Ash content, wt $\%$ $\mathrm{db}$ (dry basis). ${ }^{d}$ wt \% daf.

coated with gold, with normal X-ray incidence ( $E$ parallel to the surface). The samples were dispersed in acetone and applied to high-purity tungsten plates, and the solvent was allowed to evaporate. The nitrogen $1 \mathrm{~s} .7$ peak of $\mathrm{CN}$ in PAN at $401.4 \mathrm{eV}$ was used to calibrate the monochromator at the nitrogen $\mathrm{K}$ edge.

XPS. A VG Scientific ESCALAB 250 system equipped with a micro-focused, monochromated Al KR X-ray source $(1486.6 \mathrm{eV}$, 650 - $\mu \mathrm{m}$ spot size, $200 \mathrm{~W}$ ) and a magnetic immersion lens, which focuses electrons emitted from the sample over a cone of up to $\left(45^{\circ}\right.$ into the main lens column of the equipment, were used. The spectra were acquired in constant analyzer energy mode, with pass energies of 150 and $20 \mathrm{eV}$ for the survey and the narrow regions, respectively. The samples were mounted onto conducting double-sided adhesive tape. They did not exhibit any charging effects, and the charge compensation system (a combination of an electron and argon flood guns) was not used.

Advantage software, version 1.85, was used for digital acquisition and data processing. The surface compositions (in atomic \%) were determined using the integrated peak areas of $\mathrm{C}(1 \mathrm{~s}), \mathrm{N}(1 \mathrm{~s})$, and $\mathrm{O}(1 \mathrm{~s})$ and the respective sensitivity factors. The concentration (\%) of a particular element A was computed using

$$
\% \mathrm{~A}) \frac{\underline{I_{\mathrm{A}} / s_{\mathrm{A}}}}{\sum\left(I_{n} / s_{n}\right)} \times \quad \begin{array}{lllll}
1 & 0 & 0 & \%
\end{array}
$$

where $I_{n}$ and $s_{n}$ are the integrated peak areas and the sensitivity factors, respectively. 
Table 3. Pore Structure Characterization Data for the Active Carbons Used in This Study Determined by Adsorption of Carbon Dioxide at $273 \mathrm{~K}$ and Nitrogen at $77 \mathrm{~K}_{a}$

\begin{tabular}{|c|c|c|c|c|c|c|}
\hline \multirow{3}{*}{$\begin{array}{c}\text { carbon } \\
\text { samples }\end{array}$} & \multicolumn{2}{|c|}{$\begin{array}{l}\text { pore volume } \\
\left(\mathrm{cm}^{3} \mathrm{~g}_{-1}\right)\end{array}$} & \multirow{3}{*}{$\begin{array}{c}V \mathrm{Co} / \\
V \mathrm{~N} 2\end{array}$} & \multirow{3}{*}{$\begin{array}{c}S_{\mathrm{m} \text { ax }} \\
\left(\mathrm{m}_{2} \mathrm{~g}-1\right)\end{array}$} & \multirow{3}{*}{$\begin{array}{c}E_{0 e} \\
\left(\mathrm{~kJ} \mathrm{~mol}^{-1}\right)\end{array}$} & \multirow{3}{*}{$\begin{array}{c}X_{f} \\
(\mathrm{~nm})\end{array}$} \\
\hline & \multicolumn{2}{|c|}{$\left(\mathrm{CO}_{2}\right.$ at $\left(\mathrm{N}_{2}\right.$ at } & & & & \\
\hline & $273 \mathrm{~K})$ & $77 \mathrm{~K})$ & & & & \\
\hline$\overline{\mathrm{G}}$ & 0.334 & 0.484 & 0.690 & 898 & 27.14 & 0.42 \\
\hline $\mathrm{GN}$ & 0.262 & 0.366 & 0.716 & 704 & 24.96 & 0.47 \\
\hline GN673 & 0.235 & 0.443 & 0.530 & 631 & 24.23 & 0.49 \\
\hline PAN & 0.153 & 0.204 & 0.750 & 411 & 33.22 & 0.29 \\
\hline PANCN & 0.112 & 0.181 & 0.619 & 301 & 32.57 & 0.31 \\
\hline PANCN573 & 0.141 & 0.213 & 0.662 & 379 & 29.55 & 0.37 \\
\hline PANCN673 & 0.127 & 0.216 & 0.588 & 341 & 35.43 & 0.25 \\
\hline PANCN873 & 0.148 & 0.236 & 0.627 & 397 & 32.27 & 0.31 \\
\hline GA & 0.260 & 0.300 & 0.866 & 691 & & \\
\hline GNA & 0.200 & 0.300 & 0.666 & 529 & & \\
\hline
\end{tabular}

Density ofthe adsorbed phase $\left(\mathrm{g} \mathrm{cm}^{-3}\right)$ : nitrogen, 0.8081 ; carbon dioxide, 1.023. Obtained from an intercept of DR plot. Obtained from the Langmuir model at $\left.p / p^{0}\right) 1$. Maximum DR surface area $\left(\mathrm{CO}_{2}\right.$ at $273 \mathrm{~K}, \mathrm{CO}_{2}$ cross-sectional area $\left.1.156 \times 10^{5} \mathrm{~m}^{2} \mathrm{~mol}-1\right)$. Characteristic energy in the DR equation $\left(\mathrm{CO}_{2}\right.$ at $273 \mathrm{~K}$, 0.35 ). Xis the mean radius ofmicroporosityfrom Dubinin-Stoeckli method ${ }^{38}$ of $\mathrm{CO}_{2}$ adsorption data at $273 \mathrm{~K}$.

2.6. X-ray Diffraction (XRD). The samples were placed inside Lindemanglass capillaries (0.5-mm diameter). The XRD patterns were recorded using an INEL CPS 120 diffractometer with a cylindrical position-sensitive detector (transmission mode, Debye-Scherer geometry) and Co $\mathrm{K}_{R_{1}}$ (A ) $1.7889 \AA$ A) radiation, from 1 to $120^{\circ}(20)$.

2.7. TPD and TPR. Samples (^-5 mg, particle size $<80 \mu \mathrm{m}$ ) were heated at $30 \mathrm{~K} \mathrm{~min}^{-1}$ at atmospheric pressure in a flow (10 $\left.\mathrm{cm}^{3} \mathrm{~min}^{-1}\right)$ of a mixture of helium and neon $(99: 1, \mathrm{v} / \mathrm{v})$. Evolved gases were monitored with a Leybold quadrupole mass spectrometer. $\mathrm{N}_{2}$ was detected after selective oxidation of $\mathrm{CO}$ as $\mathrm{CO}_{2}$ on $\mathrm{MnO}_{2}$ at $393 \mathrm{~K}$. Calibration was carried out using Air Liquide standard gas mixtures of the gas in pure helium with $1 \%$ neon. The compositions of some of the carbon residues from the TPD experiments were analyzed. These samples are designated with the suffix R; that is, PANCNR represents the residue from the TPD experiment for PANCN.

\section{Results and Discussion}

\subsection{Structural and Analytical Characterization.}

3.1.1. Proximate and Elemental Analyses. Proximate and elemental analyses of the carbons used in this study and some ofthe TPD carbon residues are given in Table 2 . The oxygen contents of the low nitrogen content $[<1.05 \mathrm{wt} \%$ dry ash free (daf)] carbons G, GN, and GN673 were in the range $-3-22$ wt \% daf while the oxygen contents of the high ( $7-8$ wt $\%$ daf) nitrogen content PAN series varied in the range ${ }^{\wedge}-2-20 \mathrm{wt} \%$ daf oxygen. Heat treatment had a marked affect on the oxygen content but little or no effect on the nitrogen content of the carbons. Carbons with intermediate nitrogen contents were obtained by treating G and GN with ammonia at 1073 Kto give carbons GA and GNA, respectively. AD1073 had a high nitrogen content (^-7.2 wt \% daf) and was used as the reference carbon.

Analyses of the TPD carbon residues (HTT $1673 \mathrm{~K}$ ) showed that $15-40 \%$ of the original amounts of nitrogen were retained in the PAN series of carbons, AD1073, and GNA while the oxygen and hydrogen contents were negligible $(<0.2$ wt \%).

3.1.2. Porous Structure Characterization Data. The porous structures of the carbon materials were characterized using nitrogen adsorption at $77 \mathrm{~K}$ and $\mathrm{CO}_{2}$ adsorption at $273 \mathrm{~K}$, and the results are given in Table 3 . The total

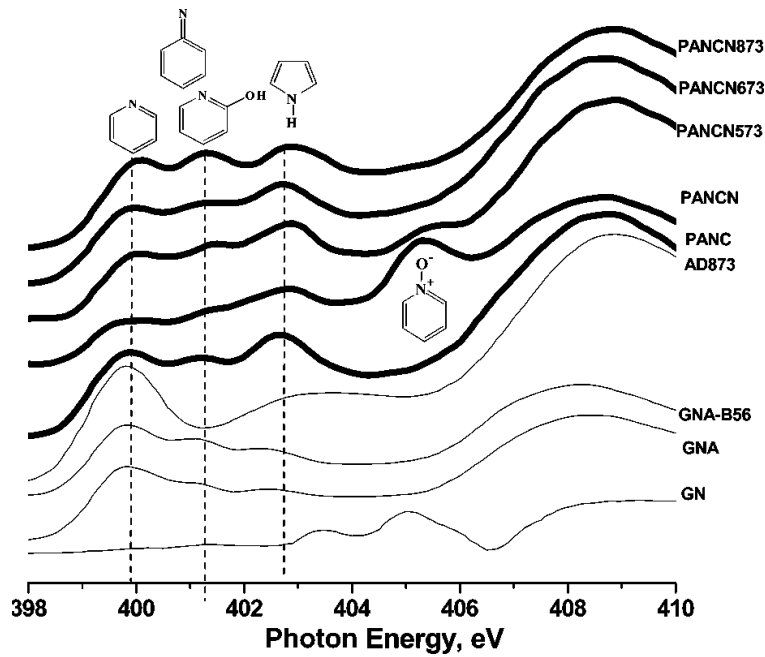

Figure 1. Nitrogen K-edge XANES spectra of PAN, the oxidized/heat treated PAN series, oxidized G(GN), ammonia treated GN(GNA), partially combusted ammonia treated GN(GNA-B56) and acridine carbons.

pore volumes obtained from nitrogen adsorption and the micropore volumes obtained from $\mathrm{CO}_{2}$ adsorption do not change greatly with heat treatment within a given series. Therefore, the reactions of surface functional groups in a given series can be studied without marked effects due to changes in porous structure. However, the total pore and micropore volumes ofthe PANC carbon series are typically $40-60 \%$ of the values in the G series of carbons. Table 3 shows the characteristic energies and mean pore radii obtained by the method of Dubinin and Stoeckli. ${ }^{38}$ The PAN carbon series have narrower average pore radii than the $\mathrm{G}$ series.

3.1.3. XANES Measurements. Nitrogen functional groups were characterized usingXANES because ofthe improved spectral resolution compared with that of XPS. Curve resolution is normally required to resolve the components in XPS, and this leads to uncertainty in the quantification of the peaks. XANES allowed clearer identification of pyridinic, pyridone, and pyrrolic groups. However, XPS studies showed that quaternary nitrogen and oxidized species $(\mathrm{N}-\mathrm{X})$ were the major surface nitrogen groups present in carbon TPD residues. The XANES spectra of these surface species have broad bands that are difficult to identify by this technique, whereas XPS allows a clear identification. Therefore, XANES was used to characterize the nitrogen species in carbons with HTT $<1273 \mathrm{~K}$ and XPS was used to characterize the TPD residues (HTT of $1673 \mathrm{~K})$

G Carbon Series. The XANES K-edge spectrum of GN is shown in Figure 1. It is apparent that the main peak at $\wedge-405 \mathrm{eV}$ has a much higher intensity than the other nitrogen peaks at $\wedge-400,401.5$, and $403.5 \mathrm{eV}$. This peak at $405 \mathrm{eV}$ is due to species incorporated by the nitric acid oxidation procedure. Comparison with reference compounds indicates that the peak is due to pyridine $N$-oxide species. ${ }^{14}$ The other peaks are assigned to pyridinic, pyridone, and pyrrolic groups. Pyridine $N$-oxide surface groups were not observed for other carbons where nitrogen is incorporated during the carbonization process.

PAN Carbon Series. The XANES spectra of the PAN series of carbons are shown in Figure 1. The spectrum of PAN has a sharp peak at $\wedge-401.4 \mathrm{eV}$ whereas carbon PANC has broader peaks at 399.8, ^-401, and ^^-403 eV. These

(38) Dubinin, M. M.; Stoeckli, H. F. J. Colloid Interface Sci, $\mathbf{1 9 8 0}$ 75,34 . 


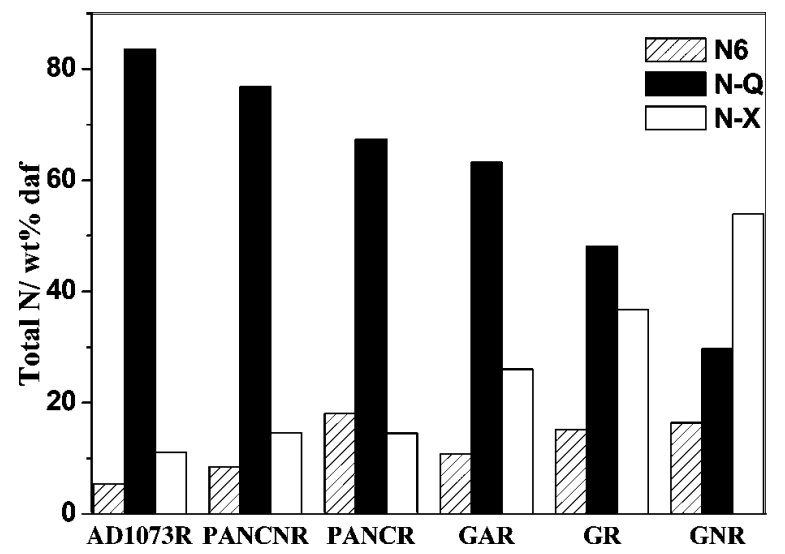

Figure 2. Nitrogen functional group compositions of the TPD carbon residues (HTT $1673 \mathrm{~K}$ ).

bands are consistent with the presence of pyridinic, pyridone (or cyanide), and pyrrolic functional groups. PANCN has peaks due to pyridinic, pyridone (or cyanide), and pyrrolic functional groups similar to PANC and an additional peak at $\wedge-405 \mathrm{eV}$, which is consistent with the presence of pyridine $N$-oxide surface species. PANCN673 showed that only pyridinic, pyridone (or cyanide), and pyrrolic functional groups were present, and the spectrum was very similar to that of PANC. The pyridine $N$-oxide functional groups decompose with heat treatment $<673$ $\mathrm{K}$ (see Figure 1).

High-Temperature Gasification Treatment Series. The XANES spectra of GNA and GNA-B56 (GNA after 56\% burnoff in air) are shown in Figure 1. The absence of a peak at $405 \mathrm{eV}$ in the spectrum of GNA indicates that pyridine $N$-oxide groups are not formed in high-temperature ammonia treatment. This is consistent with the thermal stability shown by heat treating carbon GN in an inert atmosphere. The XANES spectra of GNA and GNAB56 are quite similar except for a small increase in the peak at ${ }^{\wedge}-401 \mathrm{eV}$ in the latter which is assigned to the pyridone functionality produced during combustion. ${ }^{14}$ The XANES spectra of GA, GNA, and GNA-B56 are similar to oxidized PAN carbons in the region up to $404 \mathrm{eV}$ except that the relative intensities ofthe 401 and $402.5 \mathrm{eV}$ peaks are lower relative to the peak at $399.8 \mathrm{eV}$ due to pyridinic groups. Ammonia treatment incorporates the same functional groups as those produced by direct carbonization, but the relative concentrations are different.

Acridine Reference Carbon. The XANES spectrum of AD1073 contains a sharp peak at ^-399.8 eV corresponding to the pyridinic functionality. There is a broad, weak absorption at $\wedge-403.5 \mathrm{eV}$ and sharp peaks due to pyrrolic and pyridone (or cyano) functionalities observed for other carbons are absent. This is the simplest spectrum and is consistent with the pyridinic functional groups present in the acridine precursor.

3.1.4. XPS. Figure 2 shows the distribution of the nitrogen functional group compositions ofthe carbon TPD residues. The corresponding spectra are given in Supporting Information. The samples with higher nitrogen contents contain mainly quaternary nitrogen. The samples with low nitrogen contents contain larger amounts of the oxidized form at the expense of quaternary nitrogen. This may be due to surface oxidation.

3.1.5. XRD Measurements. The crystallinity of TPD carbon residues was examined by the XRD methods described previously. ${ }^{39}$ The 002 reflection profiles were
Table 4. XRD Parameters Obtained for TPD Carbon Residue Samples

\begin{tabular}{|c|c|c|c|c|c|c|}
\hline & \multicolumn{3}{|c|}{ observed curve } & \multicolumn{3}{|c|}{ Pearson VII amplitude } \\
\hline & $\begin{array}{l}\text { positic } \\
\left({ }^{\circ} 20\right)\end{array}$ & $\begin{array}{r}\text { fwhm } \\
\left({ }^{\circ} 20\right)\end{array}$ & $\begin{array}{l}L_{\mathrm{c}} \\
(\AA)\end{array}$ & $\begin{array}{c}\text { position } \\
\left({ }^{\circ} 20\right)\end{array}$ & $\begin{array}{r}\text { fwhm } \\
\left({ }^{\circ} 20\right)\end{array}$ & $\begin{array}{l}L_{\mathrm{c}} \\
(\AA)\end{array}$ \\
\hline AD1073R & 30.34 & 3.20 & 29.55 & 30.15 & 3.15 & 29.98 \\
\hline PAN & 29. & 5.10 & 18.51 & 29 & 5.1 & 18.21 \\
\hline PANCNR & 29.38 & 6.90 & 13.67 & 29.07 & 7.01 & 13.45 \\
\hline GR & 27.96 & 5.80 & 16.22 & 28.60 & 6.02 & 15.65 \\
\hline GNR & 29.35 & 5.10 & 18.50 & 29.12 & 4.67 & 20.17 \\
\hline GAR & 29.35 & 4.50 & 20.96 & 29.21 & 4.63 & 20.37 \\
\hline
\end{tabular}

very symmetrical, and the results calculated by the two methods were similar as shown in Table 4. AD1073R is different from the other carbons having a larger crystallite stack height $\left(L_{c}\right)$ value which is indicative of a higher degree of stacking in the microdomains in the carbon structure. Typical values of $L_{\mathrm{c}}$ and the peak centroid $\left({ }^{\circ} 20\right)$ for cokes heat treated to $1673 \mathrm{~K}$ are $L_{\mathrm{c}}(27-32 \AA)$, full width at half-maximum $\left({ }^{\circ} 20\right) \wedge-2.96-3.56$, and centroid $\left({ }^{\circ} 20\right)$ ^ $29.4-29.6^{\circ}$. AD1073R has similar structural crystallinity to graphitizable cokes, whereas the other carbons have lower crystallinity. This is related to the acridine precursor because the PAN carbons also have high nitrogen contents. Previous studies have shown that acridine carbon is optically anisotropic with mainly flowand domain-type textures. ${ }^{40}$ This indicates that the carbon has passed through a nematic discotic liquid crystal phase and, hence, is a graphitizable carbon. This is consistent with the higher crystallite stack height $\left(L_{c}\right)$ values. The other carbons have isotropic optical texture and are nongraphitizable carbons.

3.2. TPD and TPR. The integrated concentration ratios for all the TPD and TPR measurements for $\mathrm{CO}, \mathrm{CO}_{2}, \mathrm{~N}_{2}$, $\mathrm{NH}_{3}, \mathrm{H}_{2}, \mathrm{HCN}, \mathrm{CH}_{4}, \mathrm{H}_{2} \mathrm{O}$, and $\mathrm{NO}$ are given in Supporting Information. The concentration data include $\mathrm{CO}_{2 \mathrm{~A}}<675$ $\mathrm{K}$ and $\mathrm{CO}_{2 \mathrm{~B}}>675 \mathrm{~K} ; \mathrm{CO}_{2 \mathrm{~A}}<1250 \mathrm{~K}$ and $\mathrm{CO}_{\mathrm{B}}>1250 \mathrm{~K}$; $\mathrm{N}_{2 \mathrm{~A}}<1150 \mathrm{~K}$ and $\mathrm{N}_{2 \mathrm{~B}}>1150 \mathrm{~K} ; \mathrm{H}_{2 \mathrm{~A}}<1350 \mathrm{~K}, \mathrm{H}_{2 \mathrm{~B}}>1350$ $\mathrm{K}$, and $\mathrm{H}_{2 \mathrm{C}}$ consumed in TPR, corresponding to the regions of the main desorption peaks. The $\mathrm{CO}_{2} / \mathrm{CO}$ TPD ratios for the carbons used in study ranged from 0.02 to 0.79 .

3.2.1. GN and GN673 Carbons. The TPD and TPR profiles for GN and GN673 are shown in Figure 3. The TPD nitrogen species of GN are evolved over three temperature ranges, $400-800 \mathrm{~K}, 800-1200 \mathrm{~K}$, and $>1200$ $\mathrm{K}$. In the low-temperature region, 400-800 K, the NO peak was bimodal, and $\mathrm{N}_{2}, \mathrm{CO}_{2}$, and a small amount of HCN were evolved over a similar temperature range to the higher NO peak. A very small amount of NO was evolved as a very broad peak in the intermediate temperature range (800-1200 K) where $\mathrm{CO}$ was the main species evolved. The majority ofthe nitrogen species were evolved at high temperature $(>1200 \mathrm{~K})$. The $\mathrm{N}_{2}$ peaked at ${ }^{\wedge}-1510 \mathrm{~K}$ and was evolved concurrently with $\mathrm{H}_{2}$.

During TPR of GN, the low-temperature NO and $\mathrm{N}_{2}$ peaks increased compared with the corresponding TPD peaks. $\mathrm{NH}_{3}, \mathrm{HCN}, \mathrm{NO}$, and $\mathrm{N}_{2}$ were evolved in the intermediate temperature range where hydrogen consumption reaches a maximum at $\wedge-1000 \mathrm{~K}$. In the highest temperature range, the $\mathrm{N}_{2}$ evolution decreased markedly. The peak in hydrogen consumption was almost coincident with the $\mathrm{NH}_{3}, \mathrm{HCN}, \mathrm{NO}, \mathrm{N}_{2}, \mathrm{CO}$, and $\mathrm{CO}_{2}$ peaks. Significant methane production through carbon gasification was not observed. These observations are evidence for hydrogen chemisorption capping active sites, as well as gas-phase reaction of radicals/species. The $\mathrm{N}_{2}$ TPR profile also had peaks at 1035,1160 , and $1440 \mathrm{~K}$ whereas 


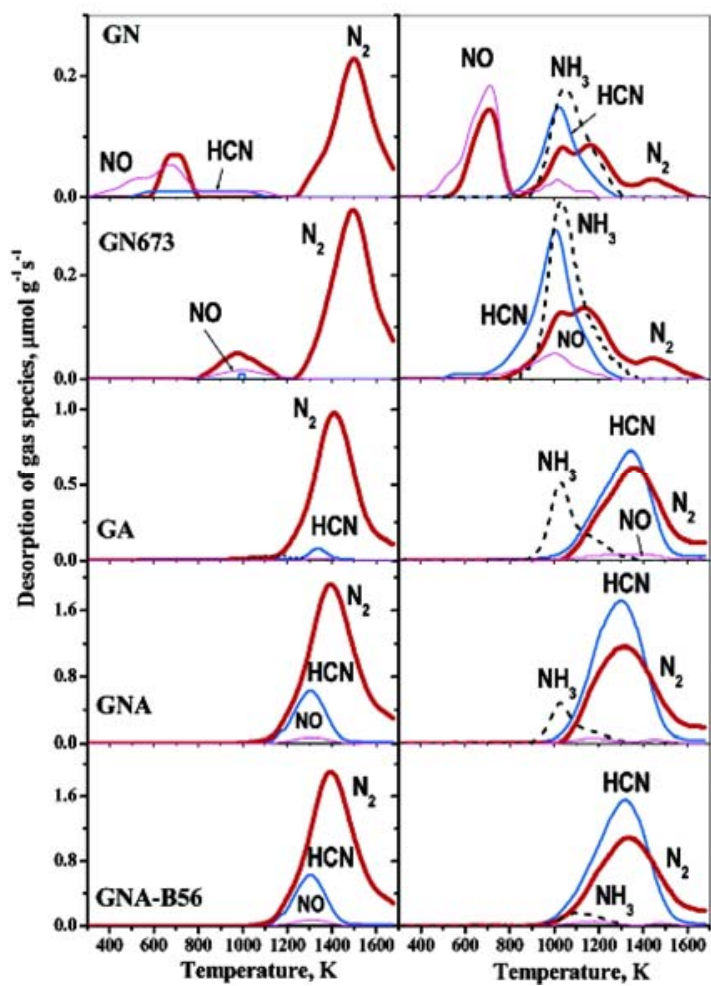

Figure 3. TPD profiles for G carbons.

the TPD profile had one main peak at ${ }^{\wedge}-1510 \mathrm{~K}$ over the temperature range. The hydrogen atmosphere perturbs nitrogen surface group reactions increasing $\mathrm{HCN}$ and $\mathrm{NH}_{3}$, while decreasing $\mathrm{N}_{2}$ formation.

3.2.2. GA, GNA, and GNA-B56 Carbons. The TPD/TPR profiles for GA and GNA are shown in Figure 3. Ammonia treatment at 1073 Kinvolves reactions ofN or $\mathrm{NH}$ radicals with graphene layers and nitrogen incorporation is larger after oxidation pretreatment (see Table 2). The nitrogen species desorb during TPD mainly as $\mathrm{N}_{2}$ (above ${ }^{\wedge}-1200 \mathrm{~K}$ ) and smaller amounts of HCN and NO. The TPD HCN/N concentration ratio for GNA is higher than for GA while the corresponding ratios are similar under TPR conditions. The other difference is the appearance of significant $\mathrm{NH}_{3}$ peaks and reduction in $\mathrm{N}_{2}$ under TPR conditions. These trends are also observed for GNA-B56 but show only minor differences in the profiles compared with those of GNA.

3.2.3. PANC and PANCN Series of Carbons. The TPD profiles of PANC and PANCN are compared in Figure 4. TPD peaks were observed for PANCN centered for NO at ${ }^{\wedge}-550 \mathrm{~K}$ and $\mathrm{N}_{2}$ at ${ }^{\wedge}-600 \mathrm{~K}$, which were not observed for the PANC. Similar NO and $\mathrm{N}_{2}$ peaks due to the decomposition of pyridine $N$-oxide groups were observed in the TPD profiles of GN as shown in Figure 3. Very little HCN was evolved over this temperature range. However, there were some differences between the low-temperature NO and $\mathrm{N}_{2}$ TPD profiles of GN and PANCN. In the case of the TPD of GN, the NO peak was bimodal with peaks at 520 and $660 \mathrm{~K}$ while the $\mathrm{N}_{2}$ peak was narrower reaching a maximum at $695 \mathrm{~K}$ with no evidence of a low-temperature component. The corresponding NO TPD peak for PANCN is broad and not resolved into components. The lowtemperature NO and $\mathrm{N}_{2}$ TPD peaks are progressively removed by heat treatment (see Figure 5). This coincides with the loss of the $405 \mathrm{eV}$ XANES peak, assigned to pyridine $N$-oxide functional groups (see Figure 1 ). These $\mathrm{NO}$ and $\mathrm{N}_{2}$ peaks coincided with peaks for the evolution

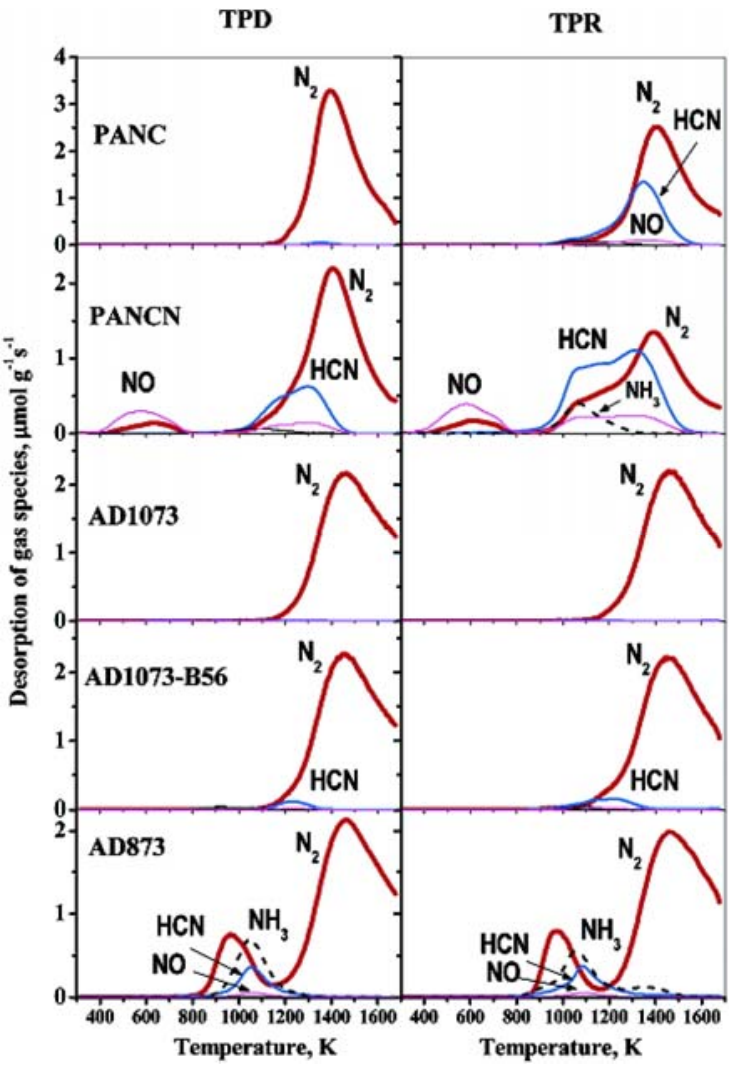

Figure 4. TPD profiles for PANC and acridine carbons.

ofCO $_{2}$ at $` 575 \mathrm{~K}$ due to decomposition ofcarboxylic surface groups. The $\mathrm{CO}_{2}$ TPD profiles for both GN and PANCN carbons have similar shapes.

The TPD profiles for nitrogen-containing species of PANC start at ${ }^{\wedge}-1200$ Kwith HCN and NO peaks at ${ }^{\wedge}-1350$ $\mathrm{K}$ and $\mathrm{N}_{2}$ at $1390 \mathrm{~K}$. The NO and larger HCN TPD profiles for PANCN are broader than for PANC carbon, and both peaks occur at ${ }^{\wedge}-1230 \mathrm{~K}$. A small $\mathrm{NH}_{3}$ peak is observed at -1090 Kin the TPD of PANCN. These peaks due to release of nitrogen-containing species are well above the corresponding $\mathrm{CO}$ profile peak at ${ }^{\wedge}-980 \mathrm{~K}$. The $\mathrm{N}_{2}$ profile peak occurred at $1410 \mathrm{~K}$ while the $\mathrm{H}_{2}$ profile was at ${ }^{\wedge}-1300 \mathrm{~K}$. The CO evolved in this temperature range was relatively small compared with the lower temperature part of the TPD profile.

TPD profiles for $\mathrm{N}_{2}$, from the PAN series of carbons, peak at $\wedge-1400$ Kand decrease to $<20 \%$ oftheir maximum value by $1673 \mathrm{~K}$, the limit of the instrument. The majority of the nitrogen in the carbons was desorbed as $\mathrm{N}_{2}$ while the rest was evolved as $\mathrm{HCN}, \mathrm{NH}_{3}$, and NO. Approximately $80 \%$ of the desorbed nitrogen species was evolved above $\sim 1200 \mathrm{~K}$. NO was $<5 \%$ and mainly desorbed over the range $500-700 \mathrm{~K}$. This $\mathrm{NO}$ is due to decomposition of pyridine $N$-oxide groups. Chemical analyses of the TPD residues (see Table 2) show that that all the samples contained ^-2.2-2.4 wt \% daf of nitrogen but very little oxygen. This indicates that ${ }^{\wedge}-28 \%$ ofthe original nitrogen was retained in the TPD residue. In excess of $95 \%$ of the total $\mathrm{CO}_{2}$ was desorbed by $873 \mathrm{~K}$. The oxygen contents of the carbons did not have an effect on desorption of $\mathrm{N}_{2}$. This is due to the limited overlap of the decomposition ranges of the functional groups.

The TPR profiles of PANC and PANCN are shown in Figures 4 and 5. The HCN peak for the TPD PANC, which showed evidence for two components, became clearly bimodal under TPR conditions with the lower peak shifting 


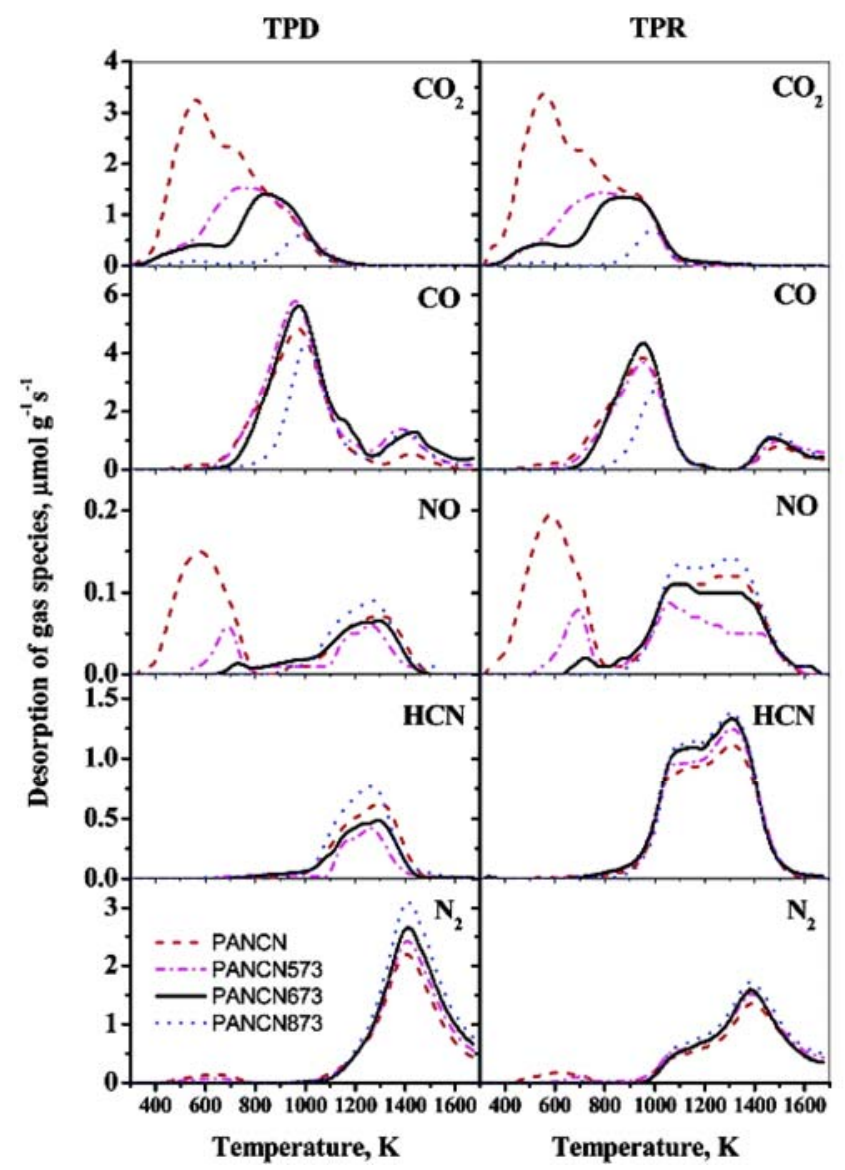

Figure 5. TPD and TPR profiles for the PANCN carbon series.

to $1100 \mathrm{~K}$ with the other peak at $1320 \mathrm{~K}$, which is higher than the corresponding TPD peak at $1275 \mathrm{~K}$. The nitrogen peak also became bimodal with a peak at ${ }^{\wedge}-1100 \mathrm{~K}$ and a much larger peak observed at $1400 \mathrm{~K}$. The latter temperature is similar to the TPD peak observed for $\mathrm{N}_{2}$. Therefore, the presence of hydrogen enhanced the formation of $\mathrm{HCN}, \mathrm{NH}_{3}$, and $\mathrm{N}_{2}$ at ${ }^{\wedge}-1100 \mathrm{~K}$ but reduced $\mathrm{N}_{2}$ evolution at $1400 \mathrm{~K}$.

Comparison of the TPD and TPR integrated concentration data for the G, PANC, and ammonia treated series of carbons show that the major differences are the increase in $\mathrm{HCN}$ and $\mathrm{NH}_{3}$ and reduction in $\mathrm{N}_{2}$ concentration under reducing conditions. This clearly indicates the role of surface $\mathrm{H}$ species in forming $\mathrm{HCN}$ and $\mathrm{NH}_{3}$. Surface oxygen species $(\mathrm{O} / \mathrm{C}$ range $0-0.2)$ do not have a significant influence on char nitrogen conversion to $\mathrm{NO}$ under the conditions used in this study.

3.2.4. Acridine Derived Carbons. The TPD and TPR profiles of the AD series are shown in Figure $4 . \mathrm{N}_{2}$ is the main TPD product, and the profile peaks at $\wedge^{\wedge}-1500 \mathrm{~K}$ and extends above the maximum temperature $(1673 \mathrm{~K})$ ofthe instrument. Analysis ofthe TPD residue shows that $\wedge^{\wedge}-40 \%$ of the original nitrogen was retained in the char at 1673 $\mathrm{K}$. XPS studies show that this stable functionality is mainly quaternary nitrogen (see Figure 2).12 Abroad, weak HCN TPD peak was observed at $1285 \mathrm{~K}$ while the hydrogen peak was at $1270 \mathrm{~K}$. The TPD profile of AD1073-B56, which has been subjected to partial combustion, displays a small HCN peak. ${ }^{14}$ Previous XANES studies have shown that partial combustion samples contain pyridone, carboxylic anhydride, and carbonyl groups. ${ }^{14,41}$ AD1073

(41) Turner, J. A.; Thomas, K. M. Langmuir 1999, 15, 6416.

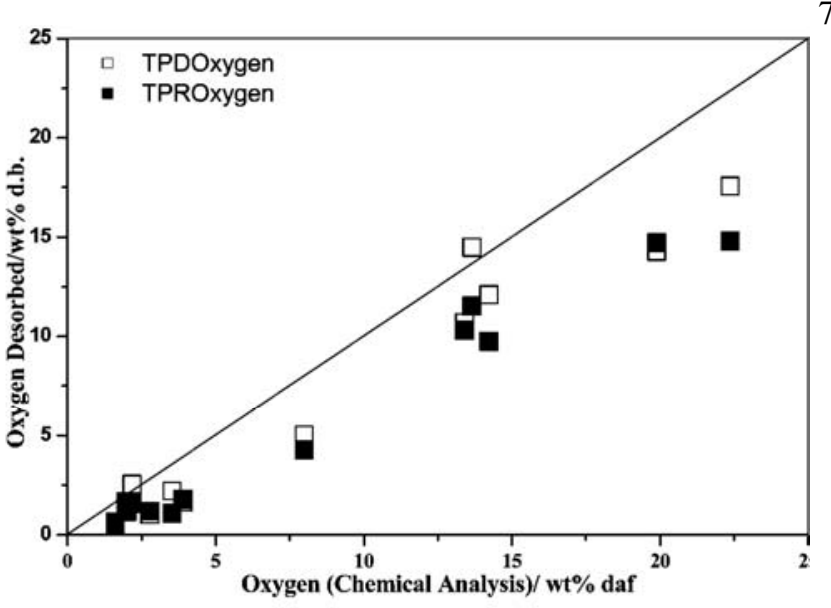

Figure 6. Comparison between TPD ( $\odot$ ) and TPR (9) data and analytical data for oxygen; solid line is $y$ ) $x$.

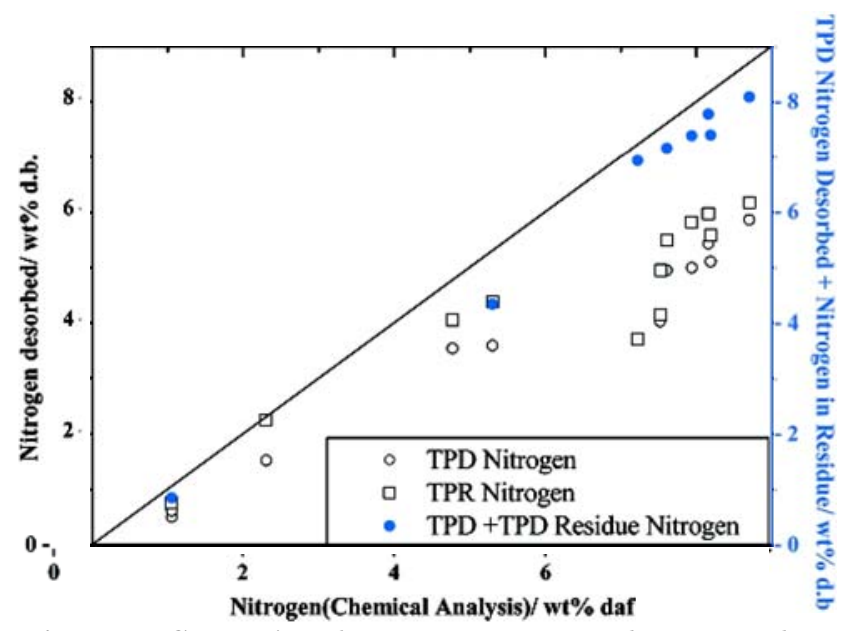

Figure 7. Comparison between TPD (0) and TPR ( $\odot)$ data, mass balance (TPD + TPD residue (b), and analytical data for nitrogen: solid line is $y$ ) $x$.

desorbs the largest amount of $\mathrm{H}_{2}$ during pyrolysis in the temperature range 800-1350 $\mathrm{K}$ due to the growth of graphene layers in the graphitizable carbon (see Supporting Information) so that TPR has little effect on the evolution of nitrogen-containing species.

3.2.5. Integrated Concentrations of TPD and TPR Species. Figure 6 shows graphs of the amount of oxygen desorbed during TPD and TPR against oxygen content of the carbon. Both graphs are linear, and the lines pass through the origin within experimental error (TPD gradient 0.828 ( 0.055 and intercept -0.44 ( 0.61 ; TPR gradient 0.746 ( 0.037 and intercept 0.41 ( 0.42 ). Chemical analysis showed that the TPD residues contained $<0.2 \mathrm{wt} \%$ oxygen but significant amounts of nitrogen (see Table 2). The oxygen mass balance difference is attributed to physisorption of oxygen-containing species, which are not detected by mass spectrometry sampling. Nitrogen-containing products do not suffer from this problem. Figure 7 shows that graphs of nitrogen desorbed in the TPD and TPR experiments versus nitrogen content of the carbon are approximately linear and pass through the origin within experimental error (TPD gradient 0.630 ( 0.043 and intercept 0.01 ( 0.28; TPR gradient 0.631 ( 0.064 and intercept 0.41 ( 0.42 ). The total nitrogen in the species detected by TPD is lower than that obtained from the corresponding chemical analysis. Figure 7 also shows a graph of the sum of nitrogen desorbed during 
TPD and nitrogen retained in the TPD carbon residue versus nitrogen in the original carbon. A linear relationship passing through the origin within experimental error (gradient ) 0.968 ( 0.039 ; intercept $0.31(0.28 ; R$ ) 0.995 ) is observed. The good mass balance indicates that all the major nitrogen species and desorption surface reactions were taken into account in the TPD experiments.

3.2.6. Reaction and Desorption ofSurface Species under Inert and Hydrogen Atmospheres. The TPD profiles of oxygen surface groups overlap, and peak deconvolution has been widely used to establish the chemical nature of the different surface oxygen species in carbons. Prior assumptions on the mechanism of desorption and on the distribution of the sites are often made. ${ }^{34}$ The problems that have been encountered are as follows:

(i) Some peaks or shoulders in the $\mathrm{CO}$ and $\mathrm{CO}_{2}$ profiles can be due to the same functionality, but with different desorption energy, and not necessarily due to different functionalities.

(ii) Many desorption processes, in particular those taking place inside pores, occur with readsorption.

(iii) Surface reactions may occur giving rise to evolution of products.

(iv) Assumptions include the presence of a continuous Gaussian distribution of desorption energies and that the preexponential factor is equal for all states.

Therefore, TPD profiles can be used to establish the total amounts of $\mathrm{CO}$ and $\mathrm{CO}_{2}$ evolved quantitatively and to identify functional groups in a semiquantitative manner. The stability of oxygen acidic functional groups is generally accepted to be

\section{pyrone/chromene > phenolic/semiquinone/carbonyl lactone/lactol $>-\mathrm{COOH}$}

In TPR, hydrogen may (a) react with the carbon active sites formed by desorption of surface complexes, (b) reduce surface complexes, and (c) induce secondary reactions. Previous comparisons of TPR and TPD for thermal desorption of $\mathrm{CO}, \mathrm{CO}_{2}$, and water vapor have shown that hydrogen may (a) make the desorption of carboxylic anhydride more facile, (b) some CO surface groups (probably semi-quinone) can be directly reduced by hydrogen to give water, and (c) net hydrogen evolution from the carbon surface starts at temperatures above 1150 $\mathrm{K}$. Hydrogen does not appear to directly reduce carboxylic acid anhydride groups, which desorb as $\mathrm{CO}$ and $\mathrm{CO}_{2}$ in a $\wedge-1: 1$ stoichiometric ratio at $\wedge_{-} 900 \mathrm{~K}_{.42,43}$ However, it chemisorbs on sites created by desorption of the species and reduces oxygen surface species at high temperature.

The TPR peaks are shifted to slightly lower temperature compared with TPD, and in the case of carbons with high concentrations of oxygen functional groups, it makes the peaks multimodal. There is little change in the profiles of $\mathrm{CO}$ and $\mathrm{CO}_{2}$ below ${ }^{\wedge}-750 \mathrm{~K}$. The amounts of $\mathrm{CO}$ evolved for TPR are lower than the corresponding values for TPD while the corresponding amounts of $\mathrm{H}_{2} \mathrm{O}$ are higher for TPR than for TPD.

The presence of a hydrogen atmosphere, compared with an inert atmosphere, shifts the $\mathrm{NH}_{3}$ and HCN peaks to lower temperature and increases the amounts of HCN and $\mathrm{NH}_{3}$ evolved with a corresponding decrease in $\mathrm{N}_{2}$. The stoichiometry of hydrogen consumed in relation to the nitrogen species desorbed is difficult to calculate because ofthe dominance ofthe $\mathrm{CO}$ species. $\mathrm{NH}_{3}$ is evolved

(42) Calo, J. M.; Cazorla-Amoros, D.; Linares-Solano, A.; RomanMartinez, M. C.; Salinas-Martinez de Lecea, C. Carbon 1997, 35, 543

(43) Otake, Y.; Jenkins, R. G. Carbon 1993, 31, 109. in the range where hydrogen is desorbed, whereas the oxygen functional groups are desorbed at lower temperature. Comparison of TPD and TPR shows that changes in surface oxygen groups have limited influence on reactions of nitrogen species.

3.3. Thermal Stability of Surface Nitrogen Species. Nitrogen retention during TPD is smaller for GNA (14\%) than for either the PAN series of carbons $(\wedge 28 \%)$ or $\mathrm{AD} 1073(42 \%)$ and is independent of the oxygen content for the PAN series. Heat treatment leads to growth of graphene layers and formation of more stable quaternary nitrogen located in the interior ofthe graphene layers. ${ }_{12,36,44}$ Quaternary nitrogen formation occurs above the ammonia treatment temperature and, therefore, is smaller for GNA. The highest nitrogen retention was observed for the acridine char, which is a graphitizable carbon.

Nitrogen functionalities such as pyridones, protonated pyridinic $-N$ and pyridinic $N$-oxides are converted to pyridinic $-N$ under mild pyrolysis conditions, and pyrrolic$N$ is converted to pyridinic-Nduring carbon structural development. 12-15,44 Pyrolysis to higher temperatures results in formation of pyridinic- $N$ located at the edge of the graphene layers or quaternary- $N$ in the interior ofthe graphene layers. ${ }^{12,43-47}$ The order of thermal stability of nitrogen functional groups is as follows:

$$
\begin{aligned}
-\mathrm{C}(N \text {-quaternary })>-\mathrm{C}(N \text {-pyridinic })> \\
\\
\quad-\mathrm{C}(\mathrm{NH} \text { pyrrolic })>-\mathrm{C}(\mathrm{NO})
\end{aligned}
$$

The nitrogen functional group composition of acridine carbons did not vary markedly for HTTs in the range 8731273 K. ${ }^{12}$ Acridine carbon AD1073 contained pyridinic ^$20 \%$, quaternary $-61 \%$, and $\mathrm{N}-\mathrm{X}-19 \%, 12$ while the composition ofthe TPD residue (AD1073R) was pyridinic ^. $5 \%$, quaternary $-84 \%$, and $\mathrm{N}-\mathrm{X}-11 \%$. TPD studies showed that only $-58 \%$ of the nitrogen in AD1073 was desorbed during TPD to $1673 \mathrm{~K}$. PANC carbon with a pyrolysis temperature of $1073 \mathrm{~K}$ had the composition pyridinic ^ ${ }^{-} 40 \%$, pyrrolic ^ $-29 \%$, quaternary $-23 \%$, and $\mathrm{N}-\mathrm{X}-9 \%$. These results are consistent with the differences observed in the XANES spectra where bands observed at ${ }^{\wedge}-401$ and $402.6 \mathrm{eV}$ are due to pyridone and pyrrolic functional groups. The composition ofthe nitrogen functional groups in the TPD residue, PANCR, was pyridinic $\wedge-18 \%$, quaternary $-67 \%$, and $\mathrm{N}-\mathrm{X}-15 \%$. Comparison of the integrated intensity data for TPD profiles of nitrogen species (see Supporting Information) and analytical data (Table 2) shows that $<10 \%$ is desorbed below ${ }^{\wedge}-1200 \mathrm{~K}$, the major portion is desorbed as $\mathrm{N}_{2}$, and some is retained in the char (HTT $1673 \mathrm{~K}$ ). $\mathrm{N}_{2}$ results from reaction of surface species rather than the direct decomposition product of a surface group. Therefore, direct desorption of nitrogen functional group species is not the major mechanism and quantification of the nitrogen functional groups from TPD profiles is not appropriate.

The conversion of quaternary nitrogen to NOx under combustion conditions is a major issue. XANES showed that pyridone, carboxylic anhydride, and carbonyl groups were formed during the carbon combustion. 14,41 These groups appear to have little effect on desorption ofnitrogen species from AD1073-B56 and GNA-B56. Kapteijn et al.48 investigated the gasification ofnitrogen-containing model

\footnotetext{
(45) Lahaye, J.; Nanse, G.; Bagrreev, A.; Strelko, V. Carbon 1999, 37,585 .

(46) Stanczyk, K; Boudou, J. P. Fuel 1994, 73, 940

(47) Schmiers, H.; Friebel, J.; Streubel, P.; Hesse, R.; Ko psel, R. Carbon 1999, 37, 1965.

(48) Laszlo, K.; Tombacz, E.; Josepovits, K. Carbon 2001, 39, 1217.

(49) Kapteijn, F.; Moulijn, J. A.; Matzner, S.; Boehm, H. P. Carbon 1999, 37, 1143 .
} 
chars where quaternary nitrogen was the major constituent, in $\mathrm{CO}_{2}$ and $\mathrm{O}_{2}$. During $\mathrm{CO}_{2}$ gasification, a slight decrease of quaternary nitrogen relative to pyridinic and pyridonic nitrogen was observed, with all nitrogen forms decreasing in absolute terms with increasing burnoff. During combustion, the absolute quantities of N-5 and $\mathrm{N}-6$ remain fairly constant, while N-Q decreases. At high burnoff levels the major functionality was pyridone in $\mathrm{O}_{2}$, while in $\mathrm{CO}_{2}$ both pyridone and pyridinic groups were present in similar amounts. Combustion and $\mathrm{CO}_{2}$ gasification gave differences in the development of the nitrogen functionality with burnoff.

The thermal stability of nitrogen surface groups needs to be considered in relation to the stability of $-\mathrm{C}(\mathrm{H})$ and various types of $-\mathrm{C}(\mathrm{O})$ surface groups because surface reactions occur. The pyridine $N$-oxide groups decompose in the temperature range $500-700 \mathrm{~K}$ to give $\mathrm{NO}$ and $\mathrm{N}_{2}$ and a very small amount of HCN. Studies of the C-NO reaction using the transient kinetic approach with ${ }_{14} \mathrm{~N}_{16} \mathrm{O}$ and $15 \mathrm{~N} 180$ have shown that $-\mathrm{C}(\mathrm{N})$ reacts with $\mathrm{NO}$ to yield $\mathrm{N}_{2 .}{ }^{22}$ Previous studies ${ }^{26}$ have shown that NO can react with char to produce $-\mathrm{CN}$ surface groups. The mechanism is consistent with desorption of $\mathrm{NO}$ and the reaction of mobile surface species $-\mathrm{C}(\mathrm{NO})$ to form $\mathrm{N}_{2}$ as follows.

$$
\begin{aligned}
\mathrm{C}(\mathrm{NO}) & +-\mathrm{C}(\mathrm{N} \mathrm{O}) \mathrm{f} \mathrm{N}_{2}+2-\mathrm{C}(\mathrm{O}) \\
& \mathrm{a} \mathrm{nd} / \mathrm{or}-\mathrm{C}(\mathrm{N})+-\mathrm{C}(\mathrm{NO}){ }^{\mathrm{f}} \mathrm{N}_{2}+-\mathrm{C}(\mathrm{O}) \\
& +-\mathrm{C}_{\text {fas }}
\end{aligned}
$$

where $-\mathrm{C}(\mathrm{N})$ and $-\mathrm{C}(\mathrm{O})$ are surface species and -Cfas is a carbon free active site. Desorption of other nitrogen surface groups from PANCN involves a small peak due to $\mathrm{NH}_{3}$ at ${ }^{\wedge}-1100 \mathrm{~K}$. This is similar to the temperature ($1140 \mathrm{~K})$ where the $\mathrm{H}_{2} \mathrm{O}$ TPD profile reaches a maximum but well below the lowest temperature peak (1300 K) due to hydrogen evolution. The corresponding HCN TPD peak occurs at ${ }^{\wedge}-1300 \mathrm{~K}$ but shows evidence for a component at lower temperature. The formation of a small amount ofNO, which peaks at ${ }^{\wedge}-1270 \mathrm{~K}$, is in the region where the $\mathrm{CO}$ and $\mathrm{H}_{2} \mathrm{O}$ peaks are decreasing and those of $\mathrm{H}_{2}$ and $\mathrm{HCN}$ are increasing. The NO peak is weak but quite distinct from the $\mathrm{NH}_{3}$ peak. $\mathrm{NH}_{3}$ is derived from either the decomposition on pyrrolic surface groups or reactions to form $\mathrm{NH}$ surface species involving - $\mathrm{C}(\mathrm{H})$ species. The hydrogen desorbed is small in the temperature range of the $\mathrm{NH}_{3}$ peak. $\mathrm{N}_{2}$ is the major desorption product and is a product of reactions of $-\mathrm{C}(\mathrm{N})$ mobile surface groups rather than direct desorption of decomposition products of surface groups. The surface groups may also react with $\mathrm{C}(\mathrm{H})$ surface species, which are increased under TPR conditions leading to higher evolution of $\mathrm{HCN}$ and $\mathrm{NH}_{3}$ with decreasing $\mathrm{N}_{2}$ evolution. These observations are indicative hydrogenation of - $\mathrm{NH}$ and - $\mathrm{C}(\mathrm{N})$ surface species. The fact that the change in HCN is much greater than $\mathrm{NH}_{3}$ suggests that surface groups $\mathrm{N}$ and $\mathrm{N}-\mathrm{H}$ are in lower concentration than $-\mathrm{C}(\mathrm{N})$. This assumes that

$\mathrm{C}(\mathrm{N})$ does not react to an appreciable extent with - $\mathrm{C}(\mathrm{H})$ to form $\mathrm{N}(\mathrm{H})$. Therefore, $\mathrm{HCN}$ is formed by either the surface reaction

$$
-\mathrm{C}(\mathrm{H})+-\mathrm{C}(\mathrm{N}){ }^{f} \mathrm{HCN}+-\mathrm{C}_{\text {fas }}
$$

where -Cfas is a free active site or desorption of HCN fragments from decomposition of functional groups in the carbon structure. Studies of the pyrolysis of pyridine in quently decomposes to HCN ${ }_{49}$ The mechanism for decomposition of pyridinic functional groups in carbons may be similar. There is little overall loss of nitrogen species (excluding pyridine $N$-oxide groups) until this temperature range as shown by TPD and chemical analysis results. XPS studies have shown that the conversion of pyrrolic groups to pyridinic groups occurs with increasing HTT showing that pyrrolic groups are less stable than pyridinic groups. ${ }^{12-14} \mathrm{~N}_{2}$ formation occurs at high temperature where oxygen surface groups are negligible mainly, via the surface reaction

$$
-\mathrm{C}(\mathrm{N})+-\mathrm{C}(\mathrm{N}){ }^{f} \mathrm{~N}_{2}+-2 \mathrm{C}_{\text {fas }}
$$

where -Cfas is a free active site and one of the surface species must be mobile. Evidence for the presence ofmobile - C(N) surface groups also comes from the observation of $\mathrm{C}_{2} \mathrm{~N}_{2}$ and $\mathrm{HCN}$ in temperature programmed combustion and $\mathrm{HCN}$ in TPD. ${ }^{27} \mathrm{C}_{2} \mathrm{~N}_{2}$ is stable at the lower temperatures in the temperature programmed combustion, but it is unstable above ${ }^{\wedge} 900 \mathrm{~K}$ and, therefore, is not observed in the TPD studies.

\section{Conclusions}

The thermal evolution, stability, and reactivity of nitrogen surface functional groups in four suites of carbons, with varying amounts of oxygen and nitrogen functional groups, were investigated by TPD and TPR. The functional groups were characterized by XANES and XPS. The TPD and TPR results are quantitative and show that the oxygen and nitrogen groups have markedly different thermal stabilities and reactivities. The decomposition temperature ranges of surface groups and the reactions of mobile surface species control the desorption products. Specific nitrogen functional groups decompose over temperature ranges to give mobile species, which may either desorb, react to form products which are desorbed, or be incorporated in the graphene layer structure. Pyridine $N$-oxide surface groups desorb $\mathrm{NO}$ and form $\mathrm{N}_{2}$ via surface reactions. Pyrrolic functional groups are preferentially converted to pyridinic and quaternary nitrogen species in the carbon structure during heat treatment. The high thermal stability of pyridinic and quaternary nitrogen surface species mainly results in mobile species at high temperatures and concurrent desorption of nitrogencontaining species with hydrogen. A major part of the oxygen surface species were desorbed at lower temperatures than those at which the nitrogen species become mobile and have little or no effect on the conversion of char nitrogen to NO under TPD conditions. In comparison, under TPR conditions, the hydrogen atmosphere shifts the peaks to slightly lower temperature and in those cases where there are oxygen functional groups in large amounts it makes the peaks multimodal. This suggests that the oxygen has a role in the region where $\mathrm{H}_{2}$ is consumed and $\mathrm{H}_{2} \mathrm{O}, \mathrm{NH}_{3}$, and $\mathrm{HCN}$ are formed. Decomposition of nitrogen surface groups at low temperature primarily leads to retention of nitrogen in the carbon structure rather than desorption of nitrogen-containing gaseous species. Significant amounts ofnitrogen species are not desorbed until $>1200 \mathrm{~K}$, and even after heat treatment to $1673 \mathrm{~K},-15$ $40 \%$ of the original nitrogen is retained in the carbon structure as quaternary nitrogen. This is probably related to carbon structural development and contrasts with oxygen surface species which are desorbed at lower 
temperatures. The assignment of TPD peaks to specific functional groups is not appropriate when the main reaction pathways are reaction of surface species to give gaseous products and incorporation of nitrogen in the carbon structure rather than direct desorption of decomposition products of surface species.
Supporting Information Available: TPD and TPR integrated concentration data and XPS spectra ofthe TPD carbon residues. This material is available free of charge via the Internet at http://pubs.acs.org. 